\title{
Charge Transport and Thermoelectric Properties of Sn-Doped Tetrahedrites $\mathrm{Cu}_{12} \mathrm{Sb}_{4-\mathrm{y}} \mathrm{Sn}_{\mathbf{y}} \mathrm{S}_{13}$
}

\author{
Hee-Jae Ahn and Il-Ho Kim* \\ Department of Materials Science and Engineering, Korea National University of Transportation, \\ Chungju, 27469, Republic of Korea
}

\begin{abstract}
In this study, tetrahedrite compounds doped with Sn were prepared by mechanical alloying and hot pressing, and their charge transport and thermoelectric properties were analyzed. X-ray diffraction analysis revealed that both the synthetic powders and sintered bodies were synthesized as a single tetrahedrite phase without secondary phases. Densely sintered specimens were obtained with relatively high densities of $99.5 \%-100.0 \%$ of the theoretical density, and the component elements were distributed uniformly. Sn was successfully substituted at the Sb site, and the lattice constant increased from 1.0348 to $1.0364 \mathrm{~nm}$. Positive signs of the Hall and Seebeck coefficients confirmed that the Sn-doped tetrahedrites were p-type semiconductors. The carrier concentration decreased from $1.28 \times 10^{19}$ to $1.57 \times 10^{18} \mathrm{~cm}^{-3}$ as the Sn content decreased because excess electrons were supplied by doping with $\mathrm{Sn}^{4+}$ at the $\mathrm{Sb}^{3+}$ site of the tetrahedrite. The Seebeck coefficient increased with increasing Sn content, and $\mathrm{Cu}_{12} \mathrm{Sb}_{3.6} \mathrm{Sn}_{0.4} \mathrm{~S}_{13}$ exhibited maximum values of 238-270 $\mathrm{HVK}^{-1}$ at temperatures of 323-723 K. However, the electrical conductivity decreased as the amount of Sn doping increased. Thus, $\mathrm{Cu}_{12} \mathrm{Sb}_{3.9} \mathrm{Sn}_{0.1} \mathrm{~S}_{13}$ exhibited the highest electrical conductivity of $(2.24-2.40) \times 10^{4}$ $\mathrm{Sm}^{-1}$ at temperatures of 323-723 K. A maximum power factor of $0.73 \mathrm{mWm}^{-1} \mathrm{~K}^{-2}$ was achieved at $723 \mathrm{~K}$ for $\mathrm{Cu}_{12} \mathrm{Sb}_{3.9} \mathrm{Sn}_{0.1} \mathrm{~S}_{13}$. Sn substitution reduced both the electronic and lattice thermal conductivities. The lowest thermal conductivity of $0.49-0.60 \mathrm{Wm}^{-1} \mathrm{~K}^{-1}$ was obtained at temperatures of $323-723 \mathrm{~K}$ for $\mathrm{Cu}_{12} \mathrm{Sb}_{3.6} \mathrm{Sn}_{0.4} \mathrm{~S}_{13}$, where the lattice thermal conductivity was dominant at $0.49-0.57 \mathrm{Wm}^{-1} \mathrm{~K}^{-1}$. As a result, a maximum dimensionless figure of merit of 0.66 was achieved at $723 \mathrm{~K}$ for $\mathrm{Cu}_{12} \mathrm{Sb}_{3.9} \mathrm{Sn}_{0.1} \mathrm{~S}_{13}$.
\end{abstract}

(Received July 12, 2021; Accepted July 28, 2021)

Keywords: thermoelectric, tetrahedrite, mechanical alloying, hot pressing

\section{Introduction}

Tetrahedrite $\left(\mathrm{Cu}_{12} \mathrm{Sb}_{4} \mathrm{~S}_{13}\right)$ is a promising thermoelectric material composed of abundant elements and has a low thermal conductivity because of its complex crystal structure (space group: $\mathrm{I} \overline{4} 3 \mathrm{~m}$ ) [13]. Lone-pair electrons of the $\mathrm{Sb}$ atoms in the tetrahedrite lead to the anharmonic vibration of $\mathrm{Cu}$ atoms located inside the triangular plane of the $\mathrm{S}$ atoms, which results in a low lattice thermal conductivity [4,5]. Considering the valence and coordination of each element, the charge balance of tetrahedrite can be expressed as $\mathrm{Cu}_{2}^{2+} \mathrm{Cu}_{10}^{+} \mathrm{Sb}_{4}^{3+} \mathrm{S}_{12}^{2-} \mathrm{S}^{2-}[6,7]$. To improve the dimensionless

- 김일호: 교수, 안희재: 학사과정

*Corresponding Author: Il-Ho Kim

[Tel: +82-10-5338-1582, E-mail: ihkim@ut.ac.kr]

Copyright (c) The Korean Institute of Metals and Materials figure of merit (ZT), partial substitutions at the $\mathrm{Cu}, \mathrm{Sb}$, or $\mathrm{S}$ sites have been made with doping elements, including transition metals such as $\mathrm{Ni}, \mathrm{Co}, \mathrm{Fe}$, and $\mathrm{Mn}$ at the $\mathrm{Cu}$ site [8-11], Te or As at the Sb site [12,13], and $\mathrm{Se}$ at the $\mathrm{S}$ site [14].

ZT is influenced by the Seebeck coefficient $(\alpha)$, electrical conductivity $(\sigma)$, thermal conductivity $(\kappa)$, and temperature (T) in Kelvin, represented as ZT $=\alpha^{2} \sigma \kappa^{-1} \mathrm{~T}$. The Seebeck coefficient and electrical conductivity have a trade-off relationship with the power factor $\left(\mathrm{PF}=\alpha^{2} \sigma\right)$ because the carrier concentration has the opposite effect on the two parameters [15]. In general, substitutional doping optimizes the carrier concentration, enhancing the PF, or it decreases the thermal conductivity, improving the thermoelectric properties.

Although many doping studies on tetrahedrites have been conducted on $\mathrm{Cu}$ sites, few studies have been performed on 
$\mathrm{Sb}$ sites. Bouyrie et al. [12] reported a ZT of 0.80 at $623 \mathrm{~K}$ for $\mathrm{Cu}_{12} \mathrm{Sb}_{3.39} \mathrm{Te}_{0.61} \mathrm{~S}_{13}$, and Lu et al. [16] obtained a ZT of 0.92 at $723 \mathrm{~K}$ for $\mathrm{Cu}_{12} \mathrm{Sb}_{3} \mathrm{TeS}_{13}$. Kwak et al. [17] reported a ZT of 0.88 at $723 \mathrm{~K}$ for $\mathrm{Cu}_{12} \mathrm{Sb}_{3.9} \mathrm{Bi}_{0.1} \mathrm{~S}_{13}$, and Kumar et al. [18] achieved a ZT of 0.84 at $673 \mathrm{~K}$ for $\mathrm{Cu}_{12} \mathrm{Sb}_{3.8} \mathrm{Bi}_{0.2} \mathrm{~S}_{13}$. In this study, tetrahedrites $\mathrm{Cu}_{12} \mathrm{Sb}_{4-\mathrm{y}} \mathrm{Sn}_{\mathrm{y}} \mathrm{S}_{13}(\mathrm{y}=0.1-0.4)$ partially substituted with $\mathrm{Sn}$ at the $\mathrm{Sb}$ site were synthesized by mechanical alloying, and sintered by hot pressing, and their charge transport and thermoelectric properties were assessed.

\section{Experimental Procedure}

Sn-doped tetrahedrites $\mathrm{Cu}_{12} \mathrm{Sb}_{4-\mathrm{y}} \mathrm{Sn}_{\mathrm{y}} \mathrm{S}_{13}(\mathrm{y}=0.1,0.2,0.3$, and 0.4 ) were synthesized by mechanical alloying. $\mathrm{Cu}(<$ $45 \mu \mathrm{m}$, purity 99.9\%, Kojundo Chemical Lab.), Sb (< $150 \mu \mathrm{m}$, purity $99.999 \%$, Kojundo Chemical Lab.), Sn (< $35 \mu \mathrm{m}$, purity $99.999 \%$, Kojundo Chemical Lab.), and S (< $75 \mu \mathrm{m}$, purity 99.99\%, Kojundo Chemical Lab.) were weighed to obtain the corresponding stoichiometric compositions. Mechanical alloying was performed at a rotation speed of $350 \mathrm{rpm}$ for $24 \mathrm{~h}$ using a planetary ball mill (Fritsch Pulverisette5) in an Ar atmosphere with stainlesssteel jars and balls. The synthesized powder was loaded into a graphite mold and subjected to consolidation using hot pressing at $723 \mathrm{~K}$ for $2 \mathrm{~h}$ under $70 \mathrm{MPa}$ in vacuum. Details of the process conditions have been reported in a previous study [19].

The phases of the synthetic powder and sintered specimens were analyzed using X-ray diffraction (XRD; Bruker D8Advance) with $\mathrm{Cu}-\mathrm{K} \alpha$ radiation. The diffraction patterns were measured in the $\theta-2 \theta$ mode $\left(2 \theta=10-90^{\circ}\right)$ with a step size of $0.02^{\circ}$. The lattice constants were analyzed using the Rietveld refinement (TOPAS program). Scanning electron microscopy (SEM; FEI Quanta400) was used to observe the fractured surfaces of the sintered specimens. The composition was analyzed using an energy-dispersive spectrometer (EDS;

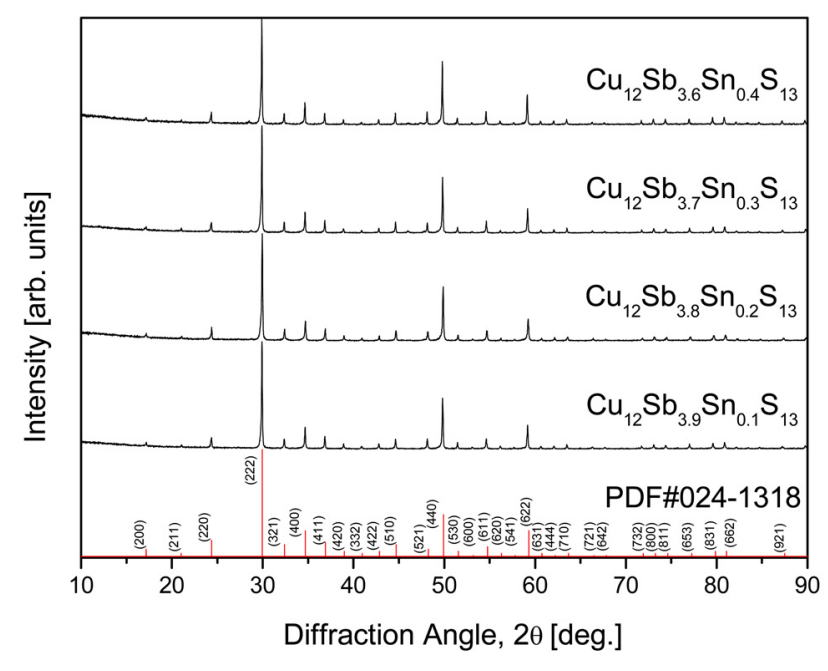

Fig. 1. XRD patterns of the $\mathrm{Cu}_{12} \mathrm{Sb}_{4-\mathrm{y}} \mathrm{Sn}_{\mathrm{y}} \mathrm{S}_{13}$ tetrahedrites synthesized by mechanical alloying and hot pressing.

Bruker Quantax200), where the energy levels of the elements were adopted as $\mathrm{Cu}-\mathrm{L} \alpha(0.928 \mathrm{eV}), \mathrm{Sb}-\mathrm{L} \alpha(3.604 \mathrm{eV}), \mathrm{Sn}-\mathrm{L} \alpha$ $(3.444 \mathrm{eV})$, and S-Ka $(2.309 \mathrm{eV})$. The Hall coefficient, carrier concentration, and mobility were measured by the van der Pauw (Keithley 7065) method by applying a constant magnetic field of $1 \mathrm{~T}$ and a current of $100 \mathrm{~mA}$. The Seebeck coefficient and electrical conductivity were measured using a ZEM-3 (Ulvac-Riko) system in a $\mathrm{He}$ atmosphere. The thermal diffusivity and specific heat were measured using the laser flash method with TC-9000H (Ulvac-Riko) equipment, and then the thermal conductivity was estimated. Finally, the $\mathrm{PF}$ and $\mathrm{ZT}$ were evaluated at temperatures in the range of 323-723 K.

\section{Results and Discussion}

Figure 1 shows the XRD analytical results for the $\mathrm{Cu}_{12} \mathrm{Sb}_{4-\mathrm{y}} \mathrm{Sn}_{\mathrm{y}} \mathrm{S}_{13}$ prepared by mechanical alloying and hot pressing. A single tetrahedrite phase (ICDD PDF\#024-1318) was identified without secondary phases, and no phase

Table 1. Chemical compositions and physical properties of $\mathrm{Cu}_{12} \mathrm{Sb}_{4-\mathrm{y}} \mathrm{Sn}_{\mathrm{y}} \mathrm{S}_{13}$.

\begin{tabular}{|c|c|c|c|c|}
\hline \multicolumn{2}{|c|}{ Composition } & \multirow{2}{*}{$\begin{array}{c}\text { Relative } \\
\text { density [\%] }\end{array}$} & \multirow{2}{*}{$\begin{array}{c}\text { Lattice } \\
\text { constant }[\mathrm{nm}]\end{array}$} & \multirow{2}{*}{$\begin{array}{l}\text { Lorenz number } \\
{\left[10^{-8} \mathrm{~V}^{2} \mathrm{~K}^{-2}\right]}\end{array}$} \\
\hline Nominal & Actual & & & \\
\hline $\mathrm{Cu}_{12} \mathrm{Sb}_{3.9} \mathrm{Sn}_{0.1} \mathrm{~S}_{13}$ & $\mathrm{Cu}_{13.59} \mathrm{Sb}_{3.07} \mathrm{Sn}_{0.10} \mathrm{~S}_{12.39}$ & 99.9 & 1.0348 & 1.82 \\
\hline $\mathrm{Cu}_{12} \mathrm{Sb}_{3.8} \mathrm{Sn}_{0.2} \mathrm{~S}_{13}$ & $\mathrm{Cu}_{12.97} \mathrm{Sb}_{2.81} \mathrm{Sn}_{0.20} \mathrm{~S}_{13.01}$ & 100.0 & 1.0359 & 1.79 \\
\hline $\mathrm{Cu}_{12} \mathrm{Sb}_{3.7} \mathrm{Sn}_{0.3} \mathrm{~S}_{13}$ & $\mathrm{Cu}_{13.48} \mathrm{Sb}_{2.68} \mathrm{Sn}_{0.31} \mathrm{~S}_{12.53}$ & 99.5 & 1.0357 & 1.73 \\
\hline $\mathrm{Cu}_{12} \mathrm{Sb}_{3.6} \mathrm{Sn}_{0.4} \mathrm{~S}_{13}$ & $\mathrm{Cu}_{13.00} \mathrm{Sb}_{2.57} \mathrm{Sn}_{0.39} \mathrm{~S}_{13.04}$ & 99.7 & 1.0364 & 1.59 \\
\hline
\end{tabular}




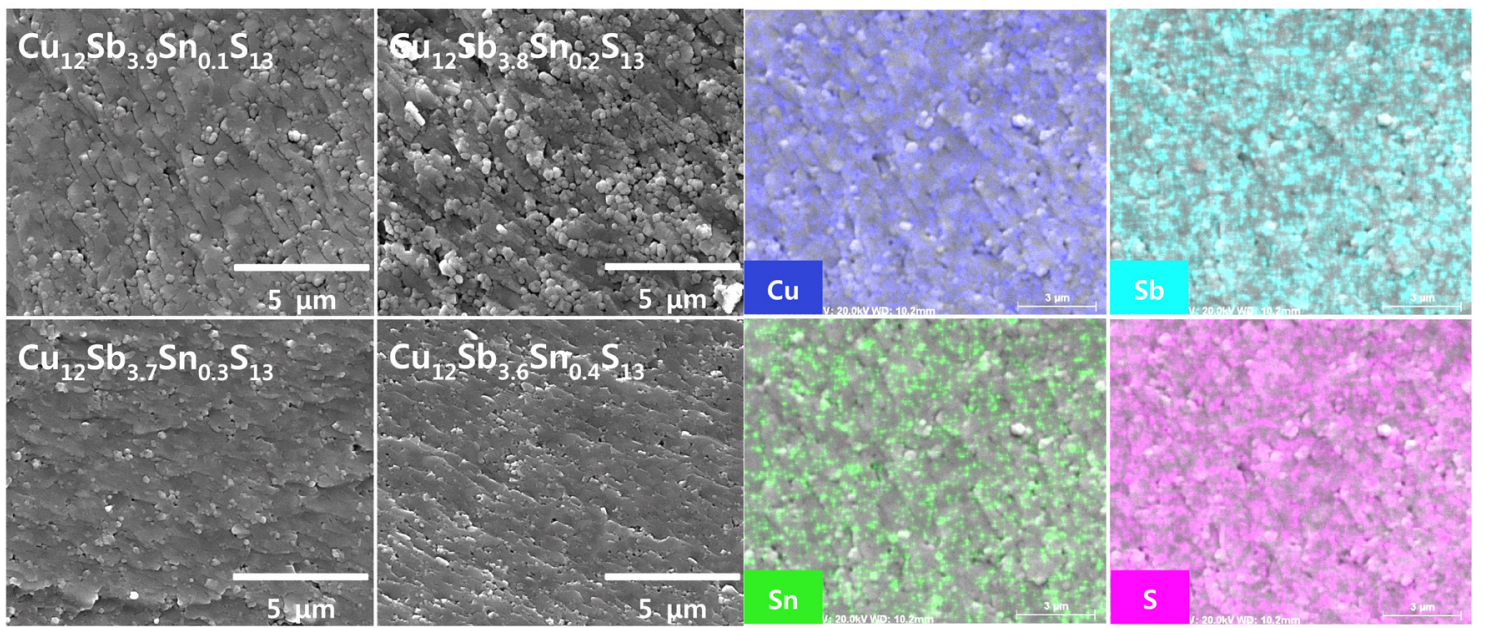

Fig. 2. $\mathrm{SEM}$ images of the fractured surfaces of $\mathrm{Cu}_{12} \mathrm{Sb}_{4-\mathrm{y}} \mathrm{Sn}_{\mathrm{y}} \mathrm{S}_{13}$, and EDS elemental maps of $\mathrm{Cu}_{12} \mathrm{Sb}_{3.9} \mathrm{Sn}_{0.1} \mathrm{~S}_{13}$.

transitions were observed at the doping content range in this study. As Table 1 shows, the lattice constant of $\mathrm{Cu}_{12} \mathrm{Sb}_{4-}$ ${ }_{\mathrm{y}} \mathrm{Sn}_{\mathrm{y}} \mathrm{S}_{13}$ increased from 1.0348 to $1.0364 \mathrm{~nm}$ as the $\mathrm{Sn}$ content increased. In our previous study [7], the lattice constant of undoped tetrahedrite $\mathrm{Cu}_{12} \mathrm{Sb}_{4} \mathrm{~S}_{13}$ was $1.0327 \mathrm{~nm}$. Thus, the lattice constant was significantly increased by $\mathrm{Sn}$ substitution at the $\mathrm{Sb}$ site. Tippireddy et al. [20] reported the ionic radii of $\mathrm{Cu}^{+}(60 \mathrm{pm}), \mathrm{Cu}^{2+}(57 \mathrm{pm}), \mathrm{Sb}^{3+}(76 \mathrm{pm}), \mathrm{Sn}^{4+}$ (69 pm), and $\mathrm{Sn}^{2+}$ (118 pm). Hansen et al. [21] suggested that $\mathrm{Sn}^{4+}$ can be doped into the $\mathrm{Cu}$ sites when no other divalent transition elements are present in the tetrahedrite system, suggesting that $\mathrm{Sn}^{2+}$ can be substituted at the $\mathrm{Sb}^{3+}$ site, and $\mathrm{Sn}^{4+}$ can be substituted for $\mathrm{Cu}^{+}$and/or $\mathrm{Cu}^{2+}$. Therefore, in this study, as the $\mathrm{Sn}$ content increased, the lattice constant increased.

Figure 2 shows SEM images of the fractured surfaces of $\mathrm{Cu}_{12} \mathrm{Sb}_{4-\mathrm{y}} \mathrm{Sn}_{\mathrm{y}} \mathrm{S}_{13}$. No remarkable difference in microstructure was observed based on Sn content, and each element was homogeneously distributed, as confirmed by EDS elemental mapping. As Table 1 shows, all the specimens reached relatively high densities of $99.5 \%-100.0 \%$, and the actual composition was similar to its nominal composition within the error ranges of the EDS analysis. Therefore, in this study, mechanical alloying and hot pressing resulted in the successful preparation of homogeneous and dense Sn-doped tetrahedrite compounds.

Figure 3 shows the carrier concentration and mobility of the $\mathrm{Cu}_{12} \mathrm{Sb}_{4-\mathrm{y}} \mathrm{Sn}_{\mathrm{y}} \mathrm{S}_{13}$. As the $\mathrm{Sn}$ content increased, the carrier

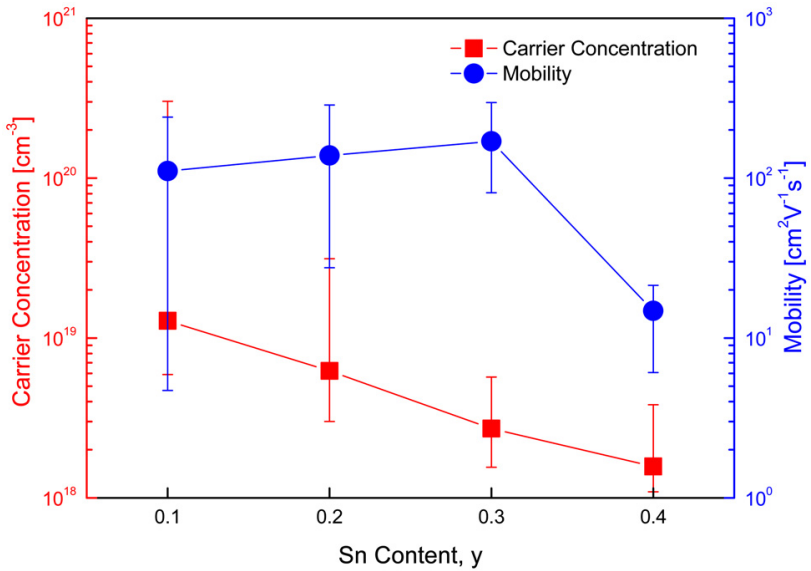

Fig. 3. Charge transport properties of $\mathrm{Cu}_{12} \mathrm{Sb}_{4-\mathrm{y}} \mathrm{Sn}_{\mathrm{y}} \mathrm{S}_{13}$.

concentration decreased from $1.28 \times 10^{19}$ to $1.57 \times 10^{18} \mathrm{~cm}^{-3}$. $\mathrm{Sn}^{4+}$ substituted at the $\mathrm{Sb}^{3+}$ site provided excess electrons, which reduced the carrier (hole) concentration due to charge compensation. Considering the ionic radii claimed by Tippireddy et al. [20] when $\mathrm{Sn}$ is doped in the tetrahedrite, either $\mathrm{Sn}^{4+}$ should be substituted at the $\mathrm{Cu}^{+}$or $\mathrm{Cu}^{2+}$ site or $\mathrm{Sn}^{2+}$ at the $\mathrm{Sb}^{3+}$ site to increase the lattice constant, as shown in this study. However, if the entirety of the doped $\mathrm{Sn}$ is substituted at the $\mathrm{Sb}^{3+}$ site into a $\mathrm{Sn}^{2+}$ state, we should observe a reduction in carrier (hole) concentration. Therefore, this study interpreted that $\mathrm{Sn}^{4+}$ was partially substituted at the $\mathrm{Cu}^{+} / \mathrm{Cu}^{2+}$ sites and/or $\mathrm{Sn}^{4+}$ was also partially substituted at the $\mathrm{Sb}^{3+}$ site. This contributed to an increase in the lattice constant and a decrease in the carrier concentration. When y 


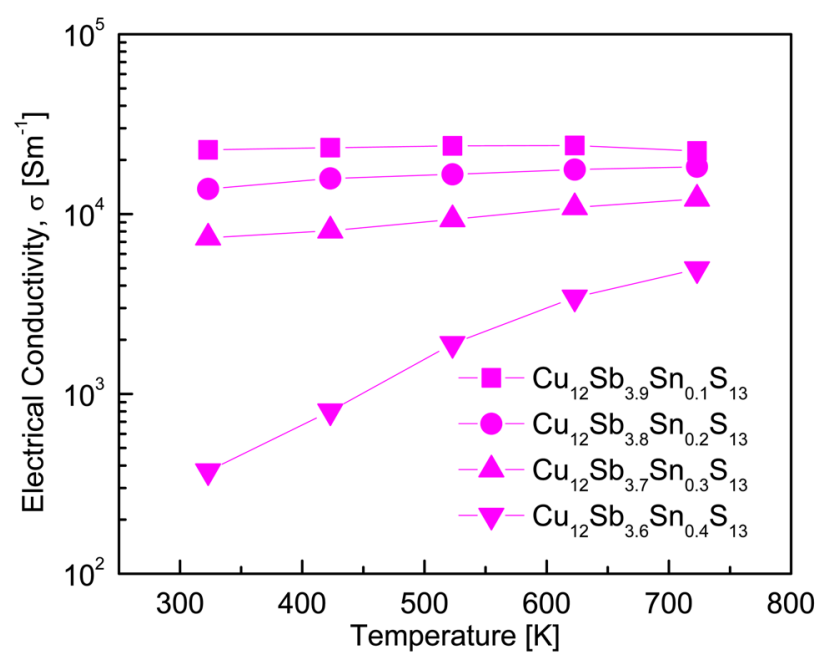

Fig. 4. Temperature dependences of the electrical conductivities of $\mathrm{Cu}_{12} \mathrm{Sb}_{4-\mathrm{y}} \mathrm{Sn}_{\mathrm{y}} \mathrm{S}_{13}$.

$\leq 0.3$, the mobility slightly increased with increasing $\mathrm{Sn}$ content but decreased when $\mathrm{y}=0.4$. The reason the mobility of $\mathrm{Cu}_{12} \mathrm{Sb}_{3.6} \mathrm{Sn}_{0.4} \mathrm{~S}_{13}$ decreased is uncertain, but it was assumed to be because of the change in the conduction mechanism.

The electrical conductivities of the $\mathrm{Cu}_{12} \mathrm{Sb}_{4-\mathrm{y}} \mathrm{Sn}_{\mathrm{y}} \mathrm{S}_{13}$ samples are shown in Fig. 4. The electrical conductivities $(\sigma)$ of semiconductors are typically affected by the carrier concentration (n) and mobility $(\mu)$, which is represented as $\sigma$ $=$ ne $\mu$ (e: electronic charge) [22]. For $\mathrm{y}=0.1$, the specimen in our study exhibited minimal temperature dependence up to $623 \mathrm{~K}$ but showed a slight decrease at temperatures above $623 \mathrm{~K}$, indicating degenerate semiconductor behavior. For y $=0.2-0.3$, the electrical conductivity slightly increased with increasing temperature. However, in the case of $y=0.4$, the electrical conductivity showed a strong positive temperature dependence, indicating non-degenerate semiconductor behavior. Thus, it was determined that the electronic conduction mechanism transitioned from a degenerate to a non-degenerate state when the tetrahedrite was doped with Sn. At a constant temperature, the electrical conductivity decreased as the Sn content increased. This is in good agreement with the decrease in the carrier concentration as the Sn doping level increased, as shown in Fig. 3.

$\mathrm{Cu}_{12} \mathrm{Sb}_{3.9} \mathrm{Sn}_{0.1} \mathrm{~S}_{13}$ exhibited the highest electrical conductivity of (2.24-2.40) $\times 10^{4} \mathrm{Sm}^{-1}$ at temperatures between 323-723 K. For the electrical conductivity of undoped $\mathrm{Cu}_{12} \mathrm{Sb}_{4} \mathrm{~S}_{13}$, Kim et al. [19] reported $(2.17-3.03) \times 10^{4} \mathrm{Sm}^{-1}$ at $323-723 \mathrm{~K}$, and $\mathrm{Pi}$

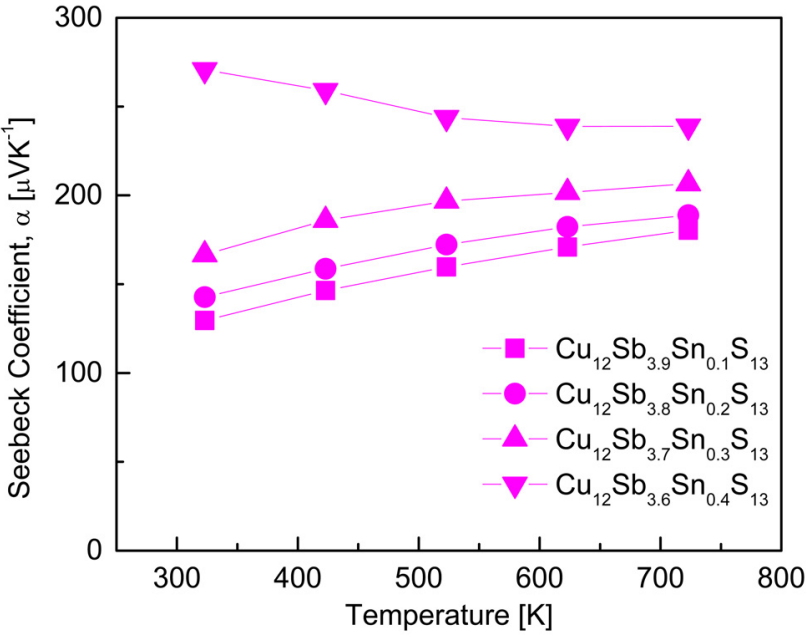

Fig. 5. Temperature dependences of the Seebeck coefficients of $\mathrm{Cu}_{12} \mathrm{Sb}_{4-\mathrm{y}} \mathrm{Sn}_{\mathrm{y}} \mathrm{S}_{13}$

et al. [23] obtained $(1.10-1.90) \times 10^{4} \mathrm{Sm}^{-1}$ at $323-723 \mathrm{~K}$. Kwak et al. [17] reported that the electrical conductivity increased with increasing $\mathrm{Bi}$ content and positive temperature dependence in the cases of $\mathrm{y} \leq 0.3$ for $\mathrm{Cu}_{12} \mathrm{Sb}_{4-\mathrm{y}} \mathrm{Bi}_{\mathrm{y}} \mathrm{S}_{13}(\mathrm{y}=$ $0.1-0.4)$ : as a result, from $(2.20-3.12) \times 10^{4} \mathrm{Sm}^{-1}$ at $323 \mathrm{~K}$ to $(2.95-3.25) \times 10^{4} \mathrm{Sm}^{-1}$ at $723 \mathrm{~K}$. However, when $\mathrm{y}=0.4$, the electrical conductivity decreased because of the formation of a secondary phase (skinnerite $\mathrm{Cu}_{3} \mathrm{SbS}_{3}$ ). Conversely, Bouyrie et al. [12] reported negative temperature dependence of the electrical conductivity for $\mathrm{Cu}_{12} \mathrm{Sb}_{4-\mathrm{x}} \mathrm{Te}_{\mathrm{x}} \mathrm{S}_{13}(\mathrm{x}=0.5-2.0)$ : from $(9.09-0.36) \times 10^{4} \mathrm{Sm}^{-1}$ at $300 \mathrm{~K}$ to $(4.54-0.42) \times 10^{4} \mathrm{Sm}^{-1}$ at $700 \mathrm{~K}$. Tippireddy et al. [20] reported that the electrical conductivity decreased with increasing Sn content and there was a negative temperature dependence for $\mathrm{Cu}_{12} \mathrm{Sb}_{4-\mathrm{x}} \mathrm{Sn}_{\mathrm{x}} \mathrm{S}_{13}$ $(\mathrm{x}=0.25-1)$ : from $(5.46-3.95) \times 10^{4} \mathrm{Sm}^{-1}$ at $373 \mathrm{~K}$ to $(4.80-$ $3.09) \times 10^{4} \mathrm{Sm}^{-1}$ at $673 \mathrm{~K}$.

Figure 5 shows the Seebeck coefficients of the $\mathrm{Cu}_{12} \mathrm{Sb}_{4-\mathrm{y}}$ $\mathrm{Sn}_{\mathrm{y}} \mathrm{S}_{13}$ samples. The Seebeck coefficient values of all specimens were positive, indicating that the major carriers were holes of p-type semiconductors. The Seebeck coefficient of a ptype semiconductor is expressed as $\alpha=(8 / 3) \pi^{2} \mathrm{k}_{\mathrm{B}}{ }^{2} \mathrm{~m}^{*} \mathrm{Te}^{-1} \mathrm{~h}^{-2}$ $(\pi / 3 n)^{2 / 3}$, where $k_{B}$ is the Boltzmann constant, $m^{*}$ is the effective carrier mass, and $h$ is the Planck constant [24]. In our study, as the temperature increased, the Seebeck coefficient increased when $\mathrm{y} \leq 0.3$, but when $\mathrm{y}=0.4$, the Seebeck coefficient decreased. In general, when the temperature was higher than a certain temperature (i.e., intrinsic transition 


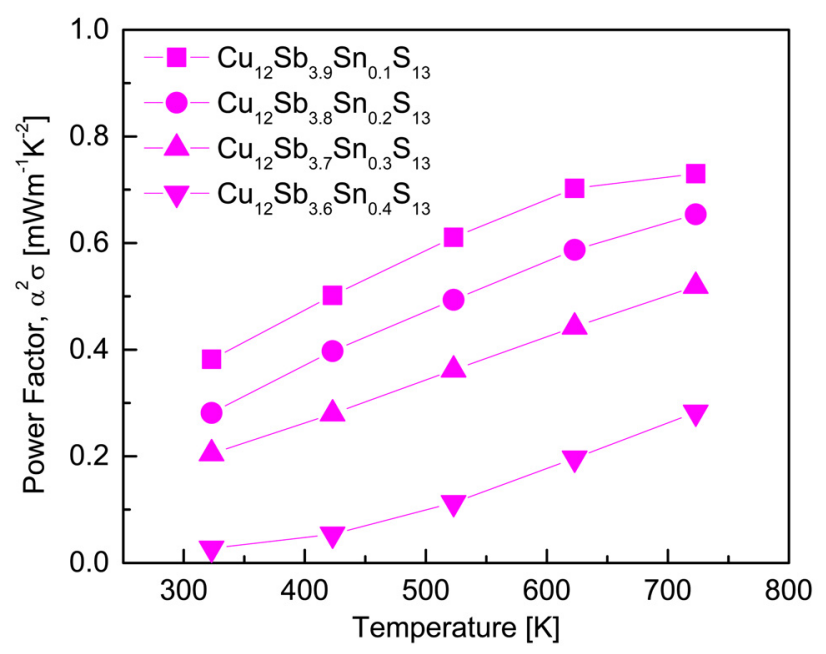

Fig. 6. Temperature dependences of the PFs of $\mathrm{Cu}_{12} \mathrm{Sb}_{4-y} \mathrm{Sn}_{\mathrm{y}} \mathrm{S}_{13}$.

temperature), the carrier concentration increased rapidly, and the Seebeck coefficient decreased. This was related to the temperature dependence of the electrical conductivity, as shown in Fig. 4.

Accordingly, the intrinsic transition seemed to occur at temperatures below $323 \mathrm{~K}$ for $\mathrm{Cu}_{12} \mathrm{Sb}_{3.6} \mathrm{Sn}_{0.4} \mathrm{~S}_{13}$. At a constant temperature, the Seebeck coefficient increased as the $\mathrm{Sn}$ content increased. Thus, $\mathrm{Cu}_{12} \mathrm{Sb}_{3.6} \mathrm{Sn}_{0.4} \mathrm{~S}_{13}$ exhibited a maximum Seebeck coefficient of $270-238 \mu \mathrm{VK}^{-1}$ at temperatures of 323-723 K. In the case of undoped $\mathrm{Cu}_{12} \mathrm{Sb}_{4} \mathrm{~S}_{13}$, Kim et al. [19] reported a Seebeck coefficient of $134-183 \mu \mathrm{VK}^{-1}$ at 323$723 \mathrm{~K}$, and Pi et al. [23] obtained $155-195 \mu \mathrm{VK}^{-1}$ at 323723 K. Kwak et al. [17] reported that the Seebeck coefficient decreased as the $\mathrm{Bi}$ content increased for $\mathrm{Cu}_{12} \mathrm{Sb}_{4-\mathrm{y}} \mathrm{Bi}_{\mathrm{y}} \mathrm{S}_{13}$ $(\mathrm{y}=0.1-0.4)$, and obtained the highest Seebeck coefficient of $153-186 \mu \mathrm{VK}^{-1}$ at $323-723 \mathrm{~K}$ for $\mathrm{Cu}_{12} \mathrm{Sb}_{3.9} \mathrm{Bi}_{0.1} \mathrm{~S}_{13}$. However, Bouyrie et al. [12] found that the Seebeck coefficient increased with increasing Te content for $\mathrm{Cu}_{12} \mathrm{Sb}_{4-\mathrm{x}} \mathrm{Te}_{\mathrm{x}} \mathrm{S}_{13}$ $(y=0.50-1.75)$. Thus, the highest Seebeck coefficient of 192$264 \mu \mathrm{VK}^{-1}$ was obtained at $300-700 \mathrm{~K}$ for $\mathrm{Cu}_{12} \mathrm{Sb}_{2.25} \mathrm{Te}_{1.75} \mathrm{~S}_{13}$. Tippireddy et al. [20] reported that the Seebeck coefficient decreased with increasing $\mathrm{Sn}$ content for $\mathrm{Cu}_{12} \mathrm{Sb}_{4-\mathrm{x}} \mathrm{Sn}_{\mathrm{x}} \mathrm{S}_{13}(\mathrm{x}=$ $0.25-1$ ), reaching a maximum value of $183 \mu \mathrm{VK}^{-1}$ at $673 \mathrm{~K}$ for $\mathrm{Cu}_{12} \mathrm{Sb}_{3.65} \mathrm{Sn}_{0.35} \mathrm{~S}_{13}$.

Figure 6 presents the PF of $\mathrm{Cu}_{12} \mathrm{Sb}_{4-\mathrm{y}} \mathrm{Sn}_{\mathrm{y}} \mathrm{S}_{13}$. Based on the temperature dependences of the electrical conductivity and Seebeck coefficient shown in Figs. 4 and Fig. 5, respectively, the PF increased with increasing temperature. Because both the Seebeck coefficient and electrical conductivity are affected by the carrier concentration, as the $\mathrm{Sn}$ content increased, the carrier concentration (i.e., electrical conductivity) decreased, which decreased the PF. In this study, a maximum $\mathrm{PF}$ of $0.38-0.73 \mathrm{mWm}^{-1} \mathrm{~K}^{-2}$ was obtained at $323-723 \mathrm{~K}$ for $\mathrm{Cu}_{12} \mathrm{Sb}_{3.9} \mathrm{Sn}_{0.1} \mathrm{~S}_{13}$. For undoped $\mathrm{Cu}_{12} \mathrm{Sb}_{4} \mathrm{~S}_{13}$, Kim et al. [19] and $\mathrm{Pi}$ et al. [23] reported $0.40-0.95 \mathrm{mWm}^{-1} \mathrm{~K}^{-2}$ and $0.26-$ $0.72 \mathrm{mWm}^{-1} \mathrm{~K}^{-2}$ at $323-723 \mathrm{~K}$, respectively. Kwak et al. [17] obtained a high $\mathrm{PF}$ of $1.02 \mathrm{mWm}^{-1} \mathrm{~K}^{-2}$ at $723 \mathrm{~K}$ for $\mathrm{Cu}_{12} \mathrm{Sb}_{3.9} \mathrm{Bi}_{0.1} \mathrm{~S}_{13}$, and Bouyrie et al. [12] reported $0.95 \mathrm{mWm}^{-}$ ${ }^{1} \mathrm{~K}^{-2}$ at $700 \mathrm{~K}$ for $\mathrm{Cu}_{12} \mathrm{Sb}_{3.5} \mathrm{Te}_{0.5} \mathrm{~S}_{13}$. Tippireddy et al. [20] achieved a very high $\mathrm{PF}$ of $1.30 \mathrm{mWm}^{-1} \mathrm{~K}^{-2}$ at $673 \mathrm{~K}$ for $\mathrm{Cu}_{12} \mathrm{Sb}_{3.65} \mathrm{Sn}_{0.35} \mathrm{~S}_{13}$, which was anomalously higher than in other studies on tetrahedrite at all temperatures examined.

Figure 7 shows the thermal conductivities of the $\mathrm{Cu}_{12} \mathrm{Sb}_{4}$ ${ }_{y} \mathrm{Sn}_{\mathrm{y}} \mathrm{S}_{13}$ samples. From the relationship $\kappa=\kappa_{\mathrm{E}}+\kappa_{\mathrm{L}}$, the lattice thermal conductivity $\left(\kappa_{\mathrm{L}}\right)$ was obtained by subtracting the electronic thermal conductivity $\left(\kappa_{\mathrm{E}}\right)$ from the total thermal conductivity $(\kappa)$. The electronic thermal conductivity was calculated using the Wiedemann-Franz law $\left(\kappa_{\mathrm{E}}=\mathrm{L} \sigma \mathrm{T}\right.$, L: Lorenz number) [25], where the Lorenz number was estimated using the formula $\mathrm{L}\left[10^{-8} \mathrm{~V}^{2} \mathrm{~K}^{-2}\right]=1.5+\exp (-|\alpha| / 116) \quad[26$, 27]. Figure 7(a) shows the total thermal conductivity of $\mathrm{Cu}_{12} \mathrm{Sb}_{4-\mathrm{y}} \mathrm{Sn}_{\mathrm{y}} \mathrm{S}_{13}$. As the temperature increased, the total thermal conductivity increased and then decreased at temperatures above $623 \mathrm{~K}$ due to the influence of the lattice thermal conductivity. At a constant temperature, the thermal conductivity decreased as the $\mathrm{Sn}$ content increased. $\mathrm{Cu}_{12} \mathrm{Sb}_{3.6} \mathrm{Sn}_{0.4} \mathrm{~S}_{13}$ exhibited the lowest thermal conductivity of $0.49-0.60 \mathrm{Wm}^{-1} \mathrm{~K}^{-1}$ at $323-723 \mathrm{~K}$, which was lower than the $0.72-0.82 \mathrm{Wm}^{-1} \mathrm{~K}^{-1}$ and $0.65-0.78 \mathrm{Wm}^{-1} \mathrm{~K}^{-1}$ of undoped $\mathrm{Cu}_{12} \mathrm{Sb}_{4} \mathrm{~S}_{13}$ as reported by Kim et al. [19] and Pi et al. [23], respectively. Kwak et al. [17] obtained a minimal thermal conductivity of $0.77-0.75 \mathrm{Wm}^{-1} \mathrm{~K}^{-1}$ at $323-723 \mathrm{~K}$ for $\mathrm{Cu}_{12}$ $\mathrm{Sb}_{3.6} \mathrm{Bi}_{0.4} \mathrm{~S}_{13}$. Tippireddy et al. [20] reported a minimum thermal conductivity of $0.61-0.79 \mathrm{Wm}^{-1} \mathrm{~K}^{-1}$ at $373-673 \mathrm{~K}$ for $\mathrm{Cu}_{12} \mathrm{Sb}_{3.75} \mathrm{Sn}_{0.25} \mathrm{~S}_{13}$ and suggested that localized energy caused by lone-pair electrons on $\mathrm{Sb}$ scattered the highvelocity acoustic phonons and hybridized with the acoustic dispersions, leading to a reduction in thermal conductivity. Therefore, this study confirmed that the thermal conductivity decreased when Sn was substituted for Sb.

As Fig. 7(b) shows, the electronic thermal conductivity 

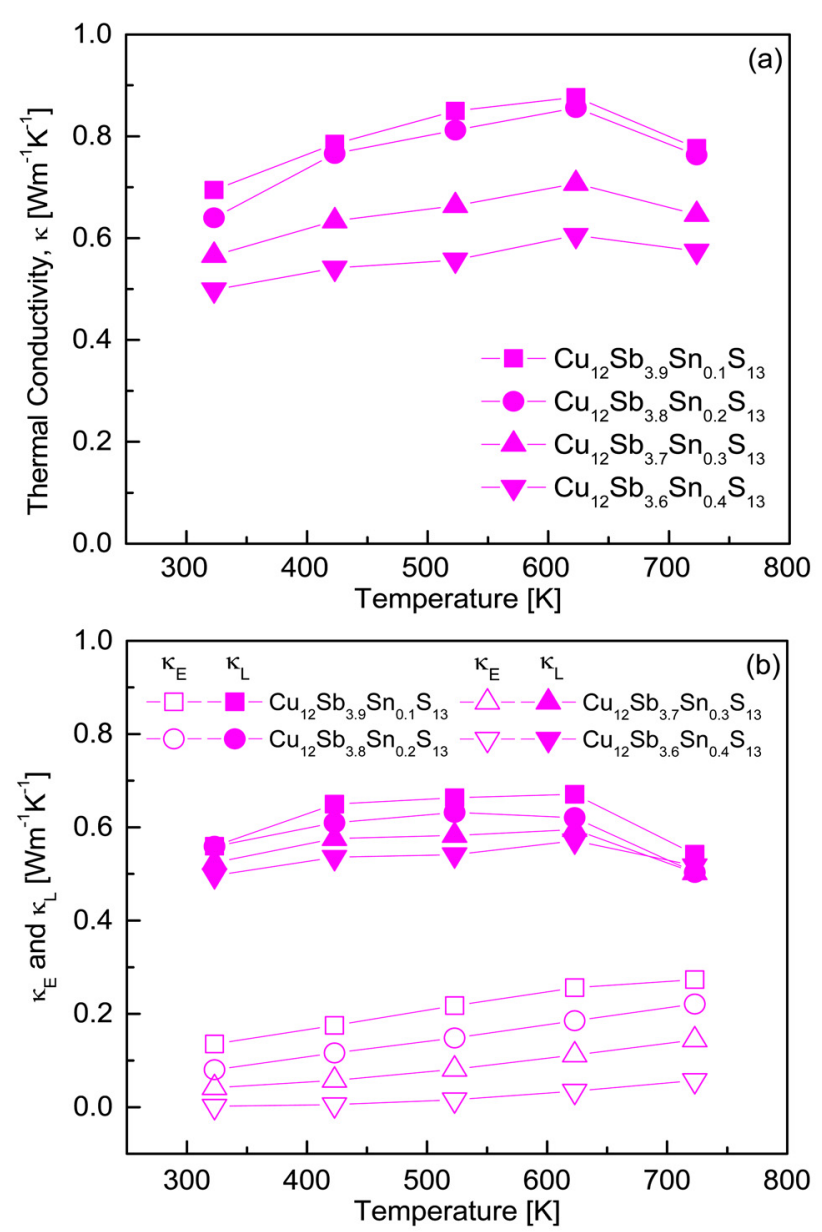

Fig. 7. Temperature dependences of the thermal conductivities of $\mathrm{Cu}_{12} \mathrm{Sb}_{4-\mathrm{y}} \mathrm{Sn}_{\mathrm{y}} \mathrm{S}_{13}$ : (a) total thermal conductivity and (b) electronic and lattice thermal conductivities.

increased with increasing temperature but decreased with increasing $\mathrm{Sn}$ content, resulting in a minimum electronic thermal conductivity of $0.002-0.057 \mathrm{Wm}^{-1} \mathrm{~K}^{-1}$ at $323-723 \mathrm{~K}$ for $\mathrm{Cu}_{12} \mathrm{Sb}_{3.6} \mathrm{Sn}_{0.4} \mathrm{~S}_{13}$. This was much lower than in other studies: $0.19-0.34 \mathrm{Wm}^{-1} \mathrm{~K}^{-1}$ at $323-723 \mathrm{~K}$ for $\mathrm{Cu}_{12} \mathrm{Sb}_{4} \mathrm{~S}_{13}$ [19], 0.19-0.40 $\mathrm{Wm}^{-1} \mathrm{~K}^{-1}$ at 323-723 $\mathrm{K}$ for $\mathrm{Cu}_{12} \mathrm{Sb}_{3.6} \mathrm{Bi}_{0.4} \mathrm{~S}_{13}$ [17], and $0.27-0.34 \mathrm{Wm}^{-1} \mathrm{~K}^{-1}$ at $373-673 \mathrm{~K}$ for $\mathrm{Cu}_{12} \mathrm{Sb}_{3} \mathrm{SnS}_{13}$ [20]. In this study, the lattice thermal conductivity decreased as the Sn content increased, resulting in a minimum lattice thermal conductivity of $0.49-0.57 \mathrm{Wm}^{-1} \mathrm{~K}^{-1}$ at $323-723 \mathrm{~K}$ for $\mathrm{Cu}_{12}$ $\mathrm{Sb}_{3.6} \mathrm{Sn}_{0.4} \mathrm{~S}_{13}$. Kim et al. [19] reported a lattice thermal conductivity of $0.43-0.59 \mathrm{Wm}^{-1} \mathrm{~K}^{-1}$ at $323-723 \mathrm{~K}$ for $\mathrm{Cu}_{12} \mathrm{Sb}_{4} \mathrm{~S}_{13}$. Kwak et al. [17] obtained a minimum lattice thermal conductivity of $0.58-0.35 \mathrm{Wm}^{-1} \mathrm{~K}^{-1}$ at $323-723 \mathrm{~K}$ for $\mathrm{Cu}_{12} \mathrm{Sb}_{3.6} \mathrm{Bi}_{0.4} \mathrm{~S}_{13}$, and Tippireddy et al. [20] achieved the

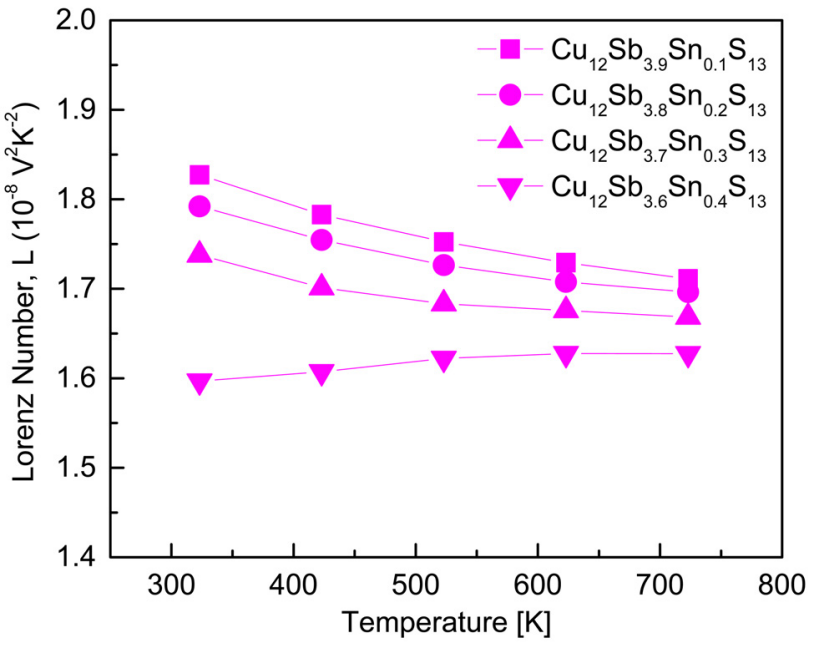

Fig. 8. Temperature dependences of the Lorenz numbers of $\mathrm{Cu}_{12} \mathrm{Sb}_{4-\mathrm{y}}$ $\mathrm{Sn}_{\mathrm{y}} \mathrm{S}_{13}$.

lowest lattice thermal conductivity of $0.23-0.32 \mathrm{Wm}^{-1} \mathrm{~K}^{-1}$ at 373-673 $\mathrm{K}$ for $\mathrm{Cu}_{12} \mathrm{Sb}_{3.75} \mathrm{Sn}_{0.25} \mathrm{~S}_{13}$.

Figure 8 shows the Lorenz numbers of $\mathrm{Cu}_{12} \mathrm{Sb}_{4-y} \mathrm{Sn}_{\mathrm{y}} \mathrm{S}_{13}$. Generally, the Lorenz number falls in the range of (1.45$2.44) \times 10^{-8} \mathrm{~V}^{2} \mathrm{~K}^{-2}$ [28]. Higher and lower Lorenz numbers indicate degenerate semiconductor or metallic behavior and non-degenerate semiconductor behavior, respectively. In this study, the Lorenz number decreased with increasing Sn content, which was considered to be a transition from degenerate to non-degenerate states. $\mathrm{Cu}_{12} \mathrm{Sb}_{3.9} \mathrm{Sn}_{0.1} \mathrm{~S}_{13}$ showed the highest Lorenz number of $(1.82-1.71) \times 10^{-8} \mathrm{~V}^{2} \mathrm{~K}^{-2}$, but $\mathrm{Cu}_{12} \mathrm{Sb}_{3.6} \mathrm{Sn}_{0.4} \mathrm{~S}_{13}$ exhibited the lowest Lorenz number of $(1.59-1.62) \times 10^{-8} \quad \mathrm{~V}^{2} \mathrm{~K}^{-2}$ at $323-723 \mathrm{~K}$. Similar Lorenz numbers were reported by Kim et al. [19] and Pi et al. [23], namely, $(1.71-1.81) \times 10^{-8} \mathrm{~V}^{2} \mathrm{~K}^{-2}$ and (1.76-1.69) $\times 10^{-8} \mathrm{~V}^{2} \mathrm{~K}^{-2}$ at 323-723 $\mathrm{K}$ for $\mathrm{Cu}_{12} \mathrm{Sb}_{4} \mathrm{~S}_{13}$, respectively, and by Kwak et al. [17], namely, $1.88 \times 10^{-8} \mathrm{~V}^{2} \mathrm{~K}^{-2}$ at $323 \mathrm{~K}$ for $\mathrm{Cu}_{12} \mathrm{Sb}_{3.7} \mathrm{Bi}_{0.3} \mathrm{~S}_{13}$.

The ZT for $\mathrm{Cu}_{12} \mathrm{Sb}_{4-\mathrm{y}} \mathrm{Sn}_{\mathrm{y}} \mathrm{S}_{13}$ is shown in Fig. 9. As the temperature increased, the $\mathrm{ZT}$ increased as the PF increased. Although the thermal conductivity decreased as the $\mathrm{Sn}$ content increased, the decrease in the PF was dominant. Therefore, the increase in Sn doping level could not further improve the ZT.

A maximum ZT of 0.66 was obtained at $723 \mathrm{~K}$ for the $\mathrm{Cu}_{12} \mathrm{Sb}_{3.9} \mathrm{Sn}_{0.1} \mathrm{~S}_{13}$. The $\mathrm{ZT}$ values of the $\mathrm{Sb}$-site-doped tetrahedrites were compared. Bouyrie et al. [12] reported that a ZT of 0.65 at $623 \mathrm{~K}$ for $\mathrm{Cu}_{12} \mathrm{Sb}_{3.5} \mathrm{Te}_{0.5} \mathrm{~S}_{13}$ was generated by 


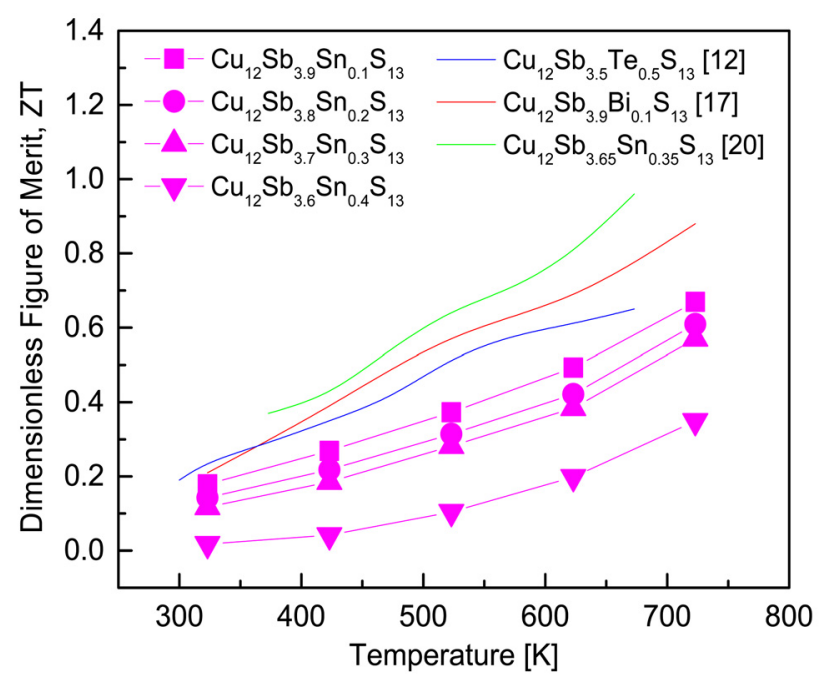

Fig. 9. Temperature dependences of the ZTs of $\mathrm{Cu}_{12} \mathrm{Sb}_{4-y} \mathrm{Sn}_{y} \mathrm{~S}_{13}$.

the multi-step annealing and spark-plasma sintering (SPS) process. Kwak et al. [17] obtained a ZT of 0.88 at $723 \mathrm{~K}$ for $\mathrm{Cu}_{12} \mathrm{Sb}_{3.9} \mathrm{Bi}_{0.1} \mathrm{~S}_{13}$ prepared by mechanical alloying and hot pressing. Tippireddy et al. [20] achieved a ZT of 0.96 at 673 $\mathrm{K}$ for $\mathrm{Cu}_{12} \mathrm{Sb}_{3.65} \mathrm{Sn}_{0.35} \mathrm{~S}_{13}$ fabricated by the annealing-millingSPS process.

\section{Conclusions}

In this study, Sn-doped tetrahedrites $\mathrm{Cu}_{12} \mathrm{Sb}_{4-\mathrm{y}} \mathrm{Sn}_{\mathrm{y}} \mathrm{S}_{13}$ $(0.1 \leq \mathrm{y} \leq 0.4)$ were synthesized by mechanical alloying and sintered by hot pressing. A single phase of tetrahedrite was obtained without secondary phases or residual elements without post-annealing treatment. The lattice constant increased as the Sn doping content increased, and Sn was substituted at the $\mathrm{Sb}$ site. As the $\mathrm{Sn}$ content increased, the carrier concentration decreased due to the charge compensation resulting from the excess supply of electrons. As the Sn content increased, mobility tended to increase when $\mathrm{y} \leq 0.3$, but decreased rapidly when $y=0.4$, which was presumed to be caused by a change in the conduction mechanism, from a degenerate to a non-degenerate state. The electrical conductivity increased as the Sn content decreased, and the temperature dependence was minimal when $y=0.1-0.3$. However, the electrical conductivity of the specimen with $y=0.4$ increased rapidly as the temperature increased, similar to the behavior of a non-degenerate semiconductor. The Seebeck coefficient increased as the Sn content increased. For $y=0.1-0.3$, the Seebeck coefficient increased as the temperature increased, but when $\mathrm{y}=0.4$, it decreased. This was because the carrier concentration increased rapidly at temperatures above the intrinsic transition temperature. The PF increased as the temperature increased, but it decreased with increasing Sn doping content. The PF was dominated by the influence of electrical conductivity. When the Sn content increased at a constant temperature, both the lattice and electronic thermal conductivities decreased. The Lorenz number decreased as the Sn content increased, changing from a degenerate to a non-degenerate state. The maximum ZT of 0.66 was obtained at $723 \mathrm{~K}$ for $\mathrm{Cu}_{12} \mathrm{Sb}_{3.9} \mathrm{Sn}_{0.1} \mathrm{~S}_{13}$.

\section{Acknowledgment}

This study was supported by the Basic Science Research Capacity Enhancement Project (National Research Facilities and Equipment Center) through the Korea Basic Science Institute funded by the Ministry of Education (Grant No. 2019R1A6C1010047).

\section{REFERENCES}

1. X. Lu and D. T. Morelli, Phys. Chem. Chem. Phys. 15, 5762 (2013).

2. X. Lu, D. T. Morelli, Y. Xia, F. Zhou, V. Ozolins, H. Chi, X. Zhou, and C. Uher, Adv. Energy Mater. 3, 342 (2013).

3. A. Pfitzner, M. Evain, and V. Petricek, Acta Crystallogr. 53, 337 (1997).

4. Y. Bouyrie, C. Candolfi, S. Pailhès, M. M. Koza, B. Malaman, A. Dauscher, J. Tobola, O. Boisron, L. Saviot, and B. Lenoir, Phys. Chem. Chem. Phys. 17, 19751 (2015).

5. W. Lai, Y. Wang, D. T. Morelli, and X. Lu, Adv. Funct. Mater. 25, 3648 (2015).

6. E. Lara-Curzio, A. F. May, O. Delaire, M. A. McGuire, X. Lu, C. Y. Liu, E. D. Case, and D. T. Morelli, J. Appl. Phys. 115, 193515 (2014).

7. S. Y. Kim, G. E. Lee, and I. H. Kim, J. Korean Phys. Soc. 74, 967 (2019).

8. C. P. L. Guelou, A. V. Powell, R. Smith, and P. Vaqueiro, J. Appl. Phys. 126, 045107 (2019).

9. E. Makovicky, K. Forchr, W. Lottermoser, and G. Amthauer, Mineral. Pertrol. 43, 73 (1990).

10. R. Chetty, A. Bali, M. H. Naik, G. Rogl, P. Rogl, M. Jain, S. 
Suwas, and R. C. Mallik, Acta Mater. 100, 266 (2015).

11. K. Suekuni, K. Tsuruta, M. Kunii, H. Nishiate, E. Nishibori, S. Maki, M. Ohta, A. Yamamoto, and M. Koyano, J. Appl. Phys. 113, 043712 (2013).

12. Y. Bouyrie, C. Candolfi, V. Ohorodniichuk, B. Malaman, A. Dauscher, J. Tobola, and B. Lenoir, J. Mater. Chem. C 3 , 10476 (2015).

13. P. Levinsky, C. Candolfi, A. Dauscher, J. Tobola, J. Hejtmanek, and B. Lenoir, Phys. Chem. Chem. Phys. 21, 4547 (2019).

14. T. K. C. Alves, G. Domingues, E. B. Lopes, and A. P. Goncalves, J. Electron. Mater. 48, 2028 (2019).

15. X. Yan, B. Poudel, Y. Ma, W. Liu, G. Joshi, H. Wang, Y. Lan, D. Wang, G. Chen, and Z. Ren, Nano Lett. 10, 3373 (2010).

16. X. Lu and D. Morelli, J. Electron. Mater. 43, 1983 (2014).

17. S. G. Kwak, J. H. Pi, G. E. Lee, and I. H. Kim, Korean J. Met. Mater. 58, 272 (2020).

18. D. S. P. Kumar, R. Chetty, P. Rogl, G. Rogl, E. Bauer, P. Malar, and R. C. Mallik, Intermetallics 78, 21 (2016).

19. S. Y. Kim, S. G. Kwak, J. H. Pi, G. E. Lee, and I. H. Kim, J.
Electron. Mater. 48, 1857 (2019).

20. S. Tippireddy, D. S. P. Kumar, A. Karati, A. Ramakrishnan, S. Sarkar, S. C. Peter, P. Malar, K. H. Chen, B. S. Murty, and R. C. Mallik, ACS Appl. Mater. Interf. 11, 21686 (2019).

21. M. K. Hansen, E. Makovicky, and S. Karup-Møller, J. Miner. Geochem. 179, 43 (2003).

22. X. Shi, H. Chen, F. Hao, R. Liu, T. Wang, P. Qiu, U. Burkhardt, Y. Grin, and L. Chen, Nat. Mater. 17, 421 (2018).

23. J. H. Pi, G. E. Lee, and I. H. Kim, J. Electron. Mater. 49, $2710(2020)$.

24. H. S. Kim, Z. M. Gibbs, Y. Tang, H. Wang, and G. J. Snyder, APL. Mater. 3, 041506 (2015)

25. T. Caillat, A. Borshchevsky, and J. P. Fleurial, J. Appl. Phys. 80, 4442 (1996).

26. B. Madaval and S. J. Hong, J. Electron. Mater. 45, 6059 (2016).

27. S. Y. Kim, J. H. Pi, G. E. Lee, and I. H. Kim, Korean J. Met. Mater. 58, 340 (2020).

28. G. S. Kumar, G. Prasad, and R. O. Pohl, J. Mater. Sci. 28, 4261 (1993). 